\title{
Factors Affecting the Behavior and Stages of Readiness to Change Exercise Behaviour among University Students
}

\author{
Aungkana Boonsem ${ }^{1} \&$ Anan Malarat $^{2}$ \\ ${ }^{1}$ King Mongkut's University of Technology Thonburi, School of Liberal Arts, Thailand \\ ${ }^{2}$ Faculty of Physical Education, Srinakharinwirot University, Thailand \\ Correspondence: Aungkana Boonsem, King Mongkut's University of Technology Thonburi, School of Liberal Arts, \\ Thailand. E-mail: aungkana.boo@kmutt.ac.th
}

Received: November 24, 2018

Accepted: December 19, 2018

Online Published: December 21, 2018

doi:10.5430/ijhe.v7n6p191

URL: https://doi.org/10.5430/ijhe.v7n6p191

\begin{abstract}
The purpose of this research was to evaluate the readiness of exercise behaviors of University students. The 400 students were selected using the formula of Yamane and stratified systematic sampling. The instrument used to collect the data was behavioral assessment. The data were analysed using an independent t-test, which resulted in a level of 0.05 level of significance. The results showed the overview of students for the stages of exercise behaviour were in the contemplation stage of $44.10 \%$. In addition, the male and female students have exercise behaviour, according to the mentioned theory were in the contemplation stage.
\end{abstract}

Keywords: behavior, stages of readiness, changing exercise behaviors, students

\section{Introduction}

According to Thailand development, science and technology are rapidly developing and progressing, which plays an important role in human life, such as the use of facilities rather than the body e.g. using elevators instead of the stairs reduces physical activity for everyone, especially adolescents. The most common problem among adolescents are not actual illnesses, but behavioral problems which pose a potential health-risk, such as a lack of exercise (Wangtanakorn, 2007). The exercise behaviors of adolescents have changed, with less exercise due to their more comfortable lifestyles and they use facilities to reduce exertion, including passive diversions such as watching TV or playing computer games. Currently, these behavioral problems are perceived as a major concern for the future health of adolescents and may have a negative impact on the health of college students corresponding to Holistic Health Risk Behavior Reduction Campaign of Thailand (National Economic and Social Development Board No.12,2017:98). The majority of college students are adolescents within an age range of 17 to 20 years of age. In early adulthood, in an age range of 21 to 25 , the transition from adolescence to adulthood-occurs between 21 to 25 years, in which there are many physical, intelligence, social and emotional changes. Health promotion at this age is important in terms of preventing access to risk behaviors and the promotion of healthy and moral behaviors, which may have positive effects in both the present and the future (Steinberg, 2007). Exercise behavior is another important health problem for students due to the fact that they focused on learning more than exercise, which is not considered to be part of physical health (Srichaisawat, 2006). Exercise is a useful activity for strengthening in the body and are increasing performance in the function of the body and to prevent non-communicable diseases (Heetaksorn, 2017). Krabounrath (2013) stated that the strengthening of physical health maintains a good shape and develops a good personality among the students. To make a student accept exercise as a part of their life, it is necessary to create a value for it, such as creating confidence and positive attitudes (Rhodes, Blanchard \& Matheson, 2006). The significance is mentioned above and inspired an interesting study on the exercise behavior of students, according to the theory of changing exercise behaviour based on the transtheoretical model (Daley \& Duda, 2006). In the development of transtheoretical model, the stages of behavior in individuals process has five distinct stages, including pre-contemplation, contemplation or preparation, action and maintenance (Kirk, Mutrie, MacIntyre, \& Fisher, 2003). If people are aware of these stages, it may lead to continuous and sustainable effects on behavioral changes. With regard to the use of the stages of theory, behavioral changes can modify the behavior was applied in the study for information on activity arrangements and suitable approaches to relevant agencies, as well as encouraging students to be healthy in both body and mind, which contributes to the development of the intellects of the students and learning and growing up to be a quality adult, which is particularly important to developing 
countries in the future. The present study aimed to evaluate the stages of readiness to change exercise behavior among students at King Mongkut's University of Technology, Thonburi (KMUTT) and compare the stages of readiness to change the exercise behavior of students, according to the variables of faculty, gender and year. To classify their relationship to stages of exercise behaviour change, and provide basic data for developing exercise practice programs for undergraduates.

\section{Method}

\subsection{Objectives}

To study factor analysis affecting the Behavior and Stages of Readiness to Change Exercise Behaviour among University Students

\subsection{Population and Samples}

A population of 11,917 undergraduate students were registered at King Mongkut's University of Technology, Thonburi. The sample group consisted of four hundred students and was acquired by purposive sampling. The sample sizes were determined using Yamane's formula at a 95\% confidence level and error of $\pm 5 \%$

\subsection{Variables Studied}

The independent variables were gender, age and education. The dependent variables were the stages of readiness to change for exercise behavior, which consisted of six steps, including pre-contemplation, contemplation or preparation, action, maintenance and relapse.

\subsection{Research Tools}

The design of this study is a survey research. The instruments included a behavioral assessment from the stages of exercise behavior, according to the theory of change and the exercise behavior of students at King Mongkut's University of Technology, Thonburi. This study was divided into two parts.

Part 1. General information about the respondents and their readiness to change their exercise behavior according to the theory of change for exercise behavior. There are divided into six stages, as follows.

Stage 1: Pre-contemplation

Stage 2: Contemplation

Stage 3: Preparation

Stage 4: Action

Stage 5: Maintenance

Stage 6: Relapse

Part 2. Students answer real questions as they actually appear. Consider the question on the left and answer it by marking $\sqrt{ }$ into the box. The criteria are as follows.

Completely True (4) means that the students have features related to questions that were at a high level (More than $75 \%$ )

True (3) means that the students have features related to questions that were at a somewhat high level (51-75\%).

Slightly True (2) means that the students have features related to questions that were at a somewhat low level. (Less than $50 \%$ )

False (1) means that the students did not have features related to the questions that were at the lowest level $(0 \%)$

\subsection{Data Analysis}

The distribution and collection of behavioral assessment form were collected data from the sample group. The data were analyzed using SPSS for Windows in term of the frequency, percentage, mean ( $\bar{x}$ ) and standard deviation (S.D.) for behavioral assessment based on the stages of exercise behavior and the theory of changes in the exercise behavior of students.

\subsection{Ethical Considerations}

The researcher clearly explained the purpose of the study to all participants. This research study was approved by the Research Ethics Committee, King Mongkut's University of Technology, Thonburi 


\section{Results}

The general information for the people measuring their readiness to change their exercise behaviour of the total number of students, $52.3 \%$ were male $(n=209)$ and $47.8 \%$ were female $(n=191)$ is shown in Table 1 . In this study, the percentage of students, including first, second, third and fourth years were $27.30 \%$ (149 students), $23.70 \%$ (95 students), $29.70 \%$ (119 students) and $19.30 \%$ (77 students) of the total, respectively. There were 189 students in the Faculty of Engineering (47.30\%), 111 students in the Faculty of Industrial Education and Technology (27.70\%), 20 students in the Faculty of Architecture and Design (5.00\%), 57 students in the Faculty of Science (14.20\%) and 23 students in the Faculty of Information Technology (5.80\%).

Table 1. General information for measuring readiness to change exercise behavior, classified by gender, year and faculty

\begin{tabular}{|c|c|c|c|c|c|c|c|c|c|c|c|c|c|c|c|c|c|c|c|c|}
\hline \multirow{3}{*}{ Faculty } & \multicolumn{4}{|c|}{ Year 1} & \multicolumn{4}{|c|}{ Year 2} & \multicolumn{4}{|c|}{ Year 3} & \multicolumn{4}{|c|}{ Year 4} & \multicolumn{4}{|c|}{ Total } \\
\hline & \multicolumn{2}{|c|}{$\operatorname{man}$} & \multicolumn{2}{|c|}{ woman } & \multicolumn{2}{|c|}{ man } & \multicolumn{2}{|c|}{ woman } & \multicolumn{2}{|c|}{$\operatorname{man}$} & \multicolumn{2}{|c|}{ woman } & \multicolumn{2}{|c|}{ man } & \multicolumn{2}{|c|}{ woman } & \multicolumn{2}{|c|}{$\operatorname{man}$} & \multicolumn{2}{|c|}{ woman } \\
\hline & number & $\%$ & number & $\%$ & number & $\%$ & number & $\%$ & number & $\%$ & number & $\%$ & number & $\%$ & number & $\%$ & number & $\%$ & number & $\%$ \\
\hline Engineering & 44 & 40.36 & 19 & 17.43 & 8 & 8.42 & 11 & 11.57 & 45 & 37.81 & 23 & 19.32 & 32 & 41.55 & 7 & 9.09 & 129 & 32.25 & 60 & 15 \\
\hline $\begin{array}{l}\text { Industrial } \\
\text { Education and } \\
\text { Technology }\end{array}$ & 5 & 4.58 & 9 & 8.25 & 19 & 20 & 43 & 45.26 & 10 & 0.84 & 13 & 10.92 & 3 & 3.89 & 9 & 11.68 & 37 & 9.25 & 74 & 18.50 \\
\hline $\begin{array}{l}\text { Architecture } \\
\text { and Design }\end{array}$ & 3 & 2.75 & 3 & 2.75 & 2 & 2.10 & 1 & 1.05 & 2 & 1.68 & 3 & 2.52 & 5 & 6.49 & 1 & 1.29 & 12 & 3 & 8 & 2 \\
\hline Science & 3 & 2.75 & 15 & 13.76 & 2 & 2.10 & 4 & 2.21 & 6 & 5.04 & 9 & 7.56 & 6 & 7.79 & 12 & 15.58 & 17 & 4.25 & 40 & 10 \\
\hline $\begin{array}{l}\text { Information } \\
\text { Technology }\end{array}$ & 6 & 5.50 & 2 & 1.83 & 2 & 2.10 & 3 & 3.15 & 5 & 4.20 & 3 & 2.52 & 1 & 1.29 & 1 & 1.29 & 14 & 3.59 & 9 & 2.25 \\
\hline \multirow{4}{*}{ Total } & 61 & 55.96 & 48 & 44.03 & 33 & 34.73 & 62 & 65.26 & 68 & 57.14 & 51 & 42.85 & 47 & 61.03 & 30 & 38.96 & 209 & 52.25 & 191 & 47.75 \\
\hline & \multirow{2}{*}{\multicolumn{4}{|c|}{109}} & \multirow{2}{*}{\multicolumn{4}{|c|}{95}} & \multirow{2}{*}{\multicolumn{4}{|c|}{119}} & \multirow{2}{*}{\multicolumn{4}{|c|}{77}} & \multirow{2}{*}{\multicolumn{4}{|c|}{400}} \\
\hline & & & & & & & & & & & & & & & & & & & & \\
\hline & \multicolumn{4}{|c|}{$27.25 \%$} & \multicolumn{4}{|c|}{$23.75 \%$} & \multicolumn{4}{|c|}{$29.75 \%$} & \multicolumn{4}{|c|}{$19.25 \%$} & \multicolumn{4}{|c|}{$100 \%$} \\
\hline
\end{tabular}

The overview of students during different stages of exercise behavior, according to the theory for changes for exercise behavior were at the second stage. The percentage of those in the contemplation stage included $44.10 \%$ (178 students), followed by the preparation stage of $29.20 \%$ (118 students), and maintenance, action, relapse and pre-contemplation, respectively. This is due to the fact that the students were in good health, but had a lack of motivation to exercise as shown in Table 2. 
Table 2. Overview of students for the stages of exercise behaviour, according to the theory of change for exercise behaviour.

\begin{tabular}{l|c|c}
\hline The stages of readiness to change exercise behaviour & Number & Percentage \\
\hline Step 1: Precontemplation & 13 & 3.10 \\
\hline Step 2: Contemplation & 178 & 44.10 \\
\hline Step 3: Preparation & 118 & 29.20 \\
\hline Step 4: Action & 31 & 7.70 \\
\hline Step 5: Maintenance & 35 & 8.70 \\
\hline Step 6: Relapse & 25 & 6.20 \\
\hline Total & 400 & 100 \\
\hline
\end{tabular}

The male and female students both demonstrated exercise behavior, according to the theory on the stages of change in exercise behavior were in the contemplation stage. The averages score were 41.12 and 48.24 , for both male and female students. The results indicated that both the male and female students had similar changes in terms of their exercise behavior (Table 3). The results of the research on first year students in the readiness stage for changes in exercise behavior in the preparation stage in Table 4. The first-year students are in the process of adapting to higher education. Their studies are at the most fundamental level and therefore they have time to exercise and participate in activities. As a result of the statistical analysis, there was a degree of readiness for change in exercise behavior in the contemplation stage for second to fourth year students because they focused exclusively on their studies and had no time for exercise.

Table 3. Overall exercise behavior of students and analysis of the factors that impact on the stages of readiness to change exercise behaviour.

\begin{tabular}{|c|c|c|c|c|c|c|c|c|c|c|c|c|}
\hline \multirow{3}{*}{$\begin{array}{c}\text { Gender } \\
\text { Number } \\
(\%)\end{array}$} & \multicolumn{12}{|c|}{ The stages of readiness to change exercise behaviour } \\
\hline & \multicolumn{2}{|c|}{ Step 1} & \multicolumn{2}{|c|}{ Step 2} & \multicolumn{2}{|c|}{ Step 3} & \multicolumn{2}{|c|}{ Step 4} & \multicolumn{2}{|c|}{ Step 5} & \multicolumn{2}{|c|}{ Step 6} \\
\hline & Number & $\%$ & Number & $\%$ & Number & $\%$ & Number & $\%$ & Number & $\%$ & Number & $\%$ \\
\hline Male & 4 & 1.93 & 86 & 41.12 & 69 & 33.00 & 18 & 8.63 & 18 & 8.62 & 14 & 6.71 \\
\hline Female & 9 & 4.71 & 92 & 48.24 & 49 & 25.74 & 13 & 6.81 & 17 & 8.94 & 11 & 5.82 \\
\hline $\begin{array}{ll}\text { Total } & 400 \\
(100) & \end{array}$ & 13 & 3.34 & 178 & 44.50 & 118 & 29.51 & 31 & 7.81 & 35 & 8.80 & 25 & 6.31 \\
\hline
\end{tabular}

Chi-Square $=5.912$ P-value $=.315$

Table 4. The stages of readiness to change exercise behavior among first to fourth year students.

\begin{tabular}{|c|c|c|c|c|c|c|c|c|c|c|c|c|}
\hline \multirow{3}{*}{ Year } & \multicolumn{12}{|c|}{ The stages of readiness to change exercise behaviour. } \\
\hline & \multicolumn{2}{|c|}{ Step 1} & \multicolumn{2}{|c|}{ Step 2} & \multicolumn{2}{|c|}{ Step 3} & \multicolumn{2}{|c|}{ Step 4} & \multicolumn{2}{|c|}{ Step 5} & \multicolumn{2}{|c|}{ Step 6} \\
\hline & Number & $\%$ & Number & $\%$ & Number & $\%$ & Number & $\%$ & Number & $\%$ & Number & $\%$ \\
\hline $1^{\text {st }}$ year & 3 & 2.81 & 39 & 35.52 & 43 & 39.41 & 4 & 3.72 & 11 & 10.11 & 9 & 8.32 \\
\hline $2^{\text {nd }}$ year & 4 & 4.21 & 43 & 45.32 & 24 & 25.31 & 11 & 11.61 & 9 & 9.52 & 4 & 4.22 \\
\hline $3^{\text {rd }}$ year & 5 & 4.21 & 56 & 47.11 & 31 & 26.12 & 10 & 8.43 & 8 & 6.73 & 9 & 7.61 \\
\hline $4^{\text {th }}$ year & 1 & 1.33 & 40 & 51.93 & 20 & 26.01 & 6 & 7.81 & 7 & 9.12 & 3 & 3.93 \\
\hline Total & 13 & 3.32 & 178 & 44.51 & 118 & 29.52 & 31 & 7.81 & 35 & 8.81 & 25 & 6.32 \\
\hline
\end{tabular}

Chi-Square $=17.037 \mathrm{sig}=.317$

The information on the exercise behavior of members of the Faculty of engineering, the Faculty of Industrial Education and Technology, the Faculty of Architecture and Design and the Faculty of Science, according to the theory of changes in exercise behavior in Table 5 were in the second stage (contemplation stage) and the third stage (preparation stage). Meanwhile, the Faculty of Information Technology also had periods of exercise behavior, which according to the theory of changes in exercise behavior were in the third stage (preparation stage) because the Faculty of Information Technology supports activities regarding physical activity, organizing sporting events and 
arranging sports facilities. As a result, the students in this faculty are at the stage of changing their exercise habits in Step Three, which is different from other faculties on campus.

Table 5. The stages of readiness to change exercise behavior by faculty.

\begin{tabular}{|c|c|c|c|c|c|c|c|c|c|c|c|c|}
\hline \multirow{3}{*}{ Faculty } & \multicolumn{12}{|c|}{ The stages of readiness to change exercise behaviour. } \\
\hline & \multicolumn{2}{|c|}{ Step 1} & \multicolumn{2}{|c|}{ Step 2} & \multicolumn{2}{|c|}{ Step 3} & \multicolumn{2}{|c|}{ Step 4} & \multicolumn{2}{|c|}{ Step 5} & \multicolumn{2}{|c|}{ Step 6} \\
\hline & Number & $\%$ & Number & $\%$ & Number & $\%$ & Number & $\%$ & Number & $\%$ & Number & $\%$ \\
\hline Engineering & 13 & 2.11 & 87 & 46.01 & 59 & 31.22 & 13 & 6.91 & 15 & 7.91 & 11 & 5.82 \\
\hline $\begin{array}{c}\text { Industrial } \\
\text { Education and } \\
\text { Technology }\end{array}$ & 4 & 3.62 & 50 & 45.02 & 31 & 27.91 & 9 & 8.11 & 11 & 9.91 & 6 & 5.41 \\
\hline $\begin{array}{l}\text { Architecture } \\
\text { and Design }\end{array}$ & 0 & 0.00 & 10 & 50.03 & 7 & 35.03 & 0 & 0.00 & 2 & 10.02 & 1 & 5.02 \\
\hline Science & 4 & 7.02 & 27 & 47.41 & 11 & 19.32 & 5 & 8.82 & 5 & 8.81 & 5 & 8.80 \\
\hline $\begin{array}{l}\text { Information } \\
\text { Technology }\end{array}$ & 1 & 4.32 & 4 & 17.41 & 10 & 43.51 & 4 & 17.44 & 2 & 8.73 & 2 & 8.71 \\
\hline Total & 13 & 3.31 & 178 & 44.52 & 118 & 29.52 & 31 & 7.81 & 35 & 8.81 & 25 & 6.32 \\
\hline
\end{tabular}

Chi-Square $=18.154 \mathrm{sig}=.577$

\section{Discussion}

The male and female students both demonstrated exercise behavior, according to the theory of change in exercise behavior were not different, which is the contemplation stage. In this stage, the students have an idea of behavior modification. They are afraid of potential health problems if they do not modify their health habits by exercising and they are not serious about exercise or the disincentives. In spite of this, students have knowledge of their exercise habits, but it is not related to exercise behavior and due to the limitations of the students in several aspects, including a strong interest in education, a lack of interest or demotivation in learning because of a lack of leisure time, which correlates with a study by Rongruang and Suknuntapung, (2011) who found that knowledge is an important factor in terms of influencing behavior. However, merely increasing knowledge cannot modify behavior. However, students also believe that regular exercise is beneficial to health and believe that people who exercise are in a better situation than people who do not exercise. There are some people that claim that exercise is healthy and very useful for daily life because it results in more energy for the body, helps with the regulation of body weight, stress management and increases immunity (Fahey, Insel \& Roth, 2007). It can also reduce risk factors for chronic diseases such as respiratory disease, diabetes, high blood pressure, cancer, obesity and osteoporosis (Penedo \& Dahn, 2005). An overview of the results found that the readiness to for exercise behavior, according to the theory of change regarding for exercise behavior, including men and women of different ages and faculties did not differ during the contemplation stage of behavior. This is a discussion between the advantages and disadvantages of the decision to simultaneously modify exercise behaviour that in the contemplation stage, people weigh up the advantages and disadvantages of exercise behaviour (Wongsaeng, 2015, Tomioka \& Maddock, 2007) In this stage, there is no actual exercise, nut they are interested in exercising within the next three to six months, correlated with the National Statistical Office (National Statistical Office, 2015) which found that working people aged between fifteen to fifty nine years had less exercise than the others. In 2007 and 2011, a total of $25.9 \%$ and $23.7 \%$ of the population exercised. Although there is a continuous campaign to exercise for health, the most of students were still in the second stage, which is contemplation stage. To find a comparison between changed behavior and self-actualization may allow them to consider the advantages and disadvantages of the original behavior with behavioral changes. Although people often procrastinate, it is still possible for them to modify their behavior. However, if a group of people are willing to accept behavioral changes, it may be considered to be beneficial for their health. These people are opening their minds to the idea of behavioral change. These people identify information about their behaviour and rationalize the advantages and disadvantages of those behaviors and to consider the pros and cons of behavioral changes that have a positive impact on general health, which correlates with the findings of (Wongsaeng, 2015, Tomioka \& Maddock, 2007) who claimed that in the second or contemplation stage, people consider the pros and cons of behavior, as well as in the behavioral changes. 
In terms of exercise behavior modification, it can be modified based on need or their intent to improve their health, which results in to readily or intent to their behaviour change for health, which results in sustainable behavioral changes. Prochaska, J. O., Redding, C. A., \& Evers, K. E. (2002) discussed the behavioral changes of people within a particular period of time and readiness for behavioral change were different. It requires a motivation to behavioral changes, a change in actual behavior and must be applied continuously. However, in continuous behavior changes, it was found that people often cease practicing. It occurs as a result of impatience, disincentives and discouragement from other people. Therefore, in order to make people accept exercise as a part of daily life, it is necessary to be aware of the importance of exercise, the creation of a positive attitude and confidence. Behavior modification is a time-consuming process due to certain behavior is habitual or familiar to people, especially the creation of exercise behavior. Meanwhile, the activity arrangement for strengthening exercises used the concepts and theories to plan and process the most effective results. The most important activity arrangement was the Transtheoretical Model (TTM), which was developed by Prochaska and DiClemente (Daley \& Duda, 2006). as a model to describe the intentions or readiness of a person to make behavioral changes. In terms of focusing on the process of behavior modification and decision-making of the individual, one of the stages of behavior modification is to determine the progress an individual is making which can determine their progress. There are processes to help relationships and provide encouragement, which are important factors for an individual attempting to change their behavior. An understanding the differences between individuals and the environment, which are main factors influencing to behavioral health promotion, are also necessary. The conceptual framework for evaluating the factors influencing to health promotion have been suggested to promote exercise behavior. By the process stage, students can actually start improving their behavioral health. Moreover, the students are familiar with the concept of behavior modification. In this stage, the students are afraid about potential health problems if they do not modify their unhealthy habits by exercising, but they are not serious about exercise or disincentives. However, students also believe that regular exercise is beneficial to health and believe that people who exercise are healthier than people who do not exercise. There were some students who were of the opinion that exercise is not healthy. In this stage, the students can be convinced and change each their mind because self-health care behavior leads to exercise.

\section{Recommendations}

1. Based on the results of the survey, the students found that their exercise behaviors were in the second stage, which is known as the contemplation stage. Health-related institutions should be involved in the preparation of activities and training to develop the knowledge or inspiration to correlate with exercise behavior among students.

2. For the educational staff, there should be a project for students to demonstrate suitable exercise behavior during the exercise behavior stage and followed up closely.

3. For those involved in management and health care organizations there should be a program provided to modify exercise behavior to be used in conjunction with health care principles including, nutrition, mental health, physical health and health check-ups before and after association with a of health behavior modification program.

\section{References}

Daley, A. J.; Duda, J. L. (2006). Self-determination, stage of readiness to change for exercise, and frequency of physical activity in young people. European Journal of Sport Science, 6(4), 231-243. https://doi.org/10.1080/17461390601012637

Fahey, T. D.; Insel, P. M.; \& Roth, W. T. (2007). Principles of Physical Fitness. Fit \& Well: Core Concepts and Labs in Physical Fitness and Wellness. (8th ed.). New York, NY: McGraw-Hill.

Heetaksorn, C. (2017). Exercise Behavior Modification and Application of Transtheroretical Model. Journal of Nursing Health Care, 35(4), 25-33. Retrieved from https://tci-thaijo.org/index.php/jnat-ned/article/view/111711/87179

Kirk, A.; Mutrie, N.; MacIntyre, P.; Fisher,M. (2003). Increasing physical activity in people with type 2 diabetes. Increasing physical activity in people with type 2 diabetes. Diabetes Care, 26(4), 1186-92. https://doi.org/10.2337/diacare.26.4.1186

Krabounrath, C. (2013). Physical Activity. Journal of Health Education, Physical Education and Recreation, 39(1), 5-15.

National Economic and Social Development Board No.12, 2017-2021:98.

National Statistical Office, Ministry of Information and Communication Technology. (2015). Exploration of sports behavior or exercise of population and mental health. Bangkok. 
Penedo, F. J.; \& Dahn, J. R. (2005). Exercise and Well-Being: A Review of Mental and Physical Health Benefits Associated with Physical Activity. Current Opinions in Psychiatry, 18(2), 189-193. https://doi.org/10.1097/00001504-200503000-00013

Prochaska, J. O., Redding, C. A., \& Evers, K. E. (2002). Health Behavior and Health Education. In K. Glanz, B. K. Rimer, and F. M. Lewis (Ed.), The transtheoretical model and stages of change (pp. 99-120) San Francisco: Jossey-Bass.

Rhodes, R.E.; Blanchard, C. M.; Matheson, D. H. (2006). A Multicomponent Model of the Theory of Planned Behaviour. British Journal of Health Psychology. 11, 119-137. https://doi.org/10.1348/135910705X52633

Rongruang, S.; Suknuntapung, S. (2011). The health promoting behavior among students at Prince Songkla University. Journal of Behavioral Science, 17(1), 110-123.

Steinberg, L. (2007). Risk taking in adolescence: New perspectives from brain and behavioral science. Current Directions in Psychological Science, 16(2), 55-59. https://doi.org/10.1111/j.1467-8721.2007.00475.x

Srichaisawat, P. (2006). Factors Affecting Exercise Behaviors of Undergraduate Students, Srinakharinwirot University. Journal of faculty of physical education, 9(2), 5-18.

Tomioka, M.; Maddock, J. (2007). Predictors of Smoking and Alcohol Use in Japanese and Japanese-American College Student. Californian Journal of Health Promotion, 5(2), 45-57. Retrieved from http://cjhp.fullerton.edu/Volume5_2007/Issue2/045-057-tomioka.pdf

Wongsaenga, Y. (2015). An Analysis of Variables Discriminating Between Quitter And Non-Quitter Groups Among Thai Alcohol-Dependent Smokers. Procedia - Social and Behavioral Sciences, 191, 202 - 207. https://doi.org/10.1016/j.sbspro.2015.04.624

Wungthanakorn, S. (2007). Health Risk Behaviors of Undergraduate Students in Southern Thailand health Risk Behaviors of Undergraduate Students in Southern Thailand. Journal of Health Promotion and Environmental Health, 30(3), 68-79. 